\title{
Machine Learning and Artificial Intelligence in Banking
}

\section{Praveen Kumar Donepudi}

Principal Architect, IT Infrastructure Services, Cognizant Technology Solutions, United States

\begin{abstract}
Machine Learning and Artificial Intelligence applications in the financial sector have been thriving in the recent past. Their immense power has been harnessed in these institutions to offer business solutions in front end and back end processes to create efficiency and improve customer experience. This article will lay bare the applications of Machine Learning and Artificial Intelligence and evaluate its utility in different banking industry functional areas and frame how these institutions effectively use computational intelligence to improve their business. While traditional banking institutions are quickly catching up with the computational intelligence technologies with products like Chatbot, fintech companies, which seem to have embrace A.I. a long time ago, plays a critical role through its innovation and contribute substantially to financial intelligence. In conclusion, we can aptly say that Machine Learning and Artificial Intelligence technologies are taking over the banking sector, and it seems like there's nothing we can do about it.
\end{abstract}

Key words

Machine Learning, Artificial Intelligence, Financial Sector

$12 / 31 / 2017$

Source of Support: None, No Conflict of Interest: Declared

This article is licensed under a Creative Commons Attribution-NonCommercial 4.0 International License.

Attribution-NonCommercial (CC BY-NC) license lets others remix, tweak, and build upon work non-commercially, and although the new works must also acknowledge \& be non-commercial.

\section{INTRODUCTION}

Machine Learning (ML) and Artificial Intelligence (A.I.) applications in the financial sector have been thriving in the recent past. Their immense power has been harnessed in these institutions to offer business solutions in front end and back end processes to create efficiency and improve customer experience. In recent times, we have witnessed how computational intelligence is the most valuable enabler to achieve a competitive edge by leveraging its decision-making capabilities. With tremendous results, we see that ML and A.I. are set to take over the banking industry by storm right before our eyes. This article will lay bare the applications of Machine Learning and Artificial Intelligence and evaluate its utility in different banking industry functional areas and frame how these institutions 
effectively use computational intelligence to improve their business (Castelli et al., 2016; Donepudi, 2016). No doubt, ML and A.I. have revolutionized the banking industry. This revolution has dramatically improved the banking experience in many ways. Although most financial institutions are still grappling with adopting computational intelligence technologies, its application is sweeping the industry like a wildfire.

Therefore, it is fair to say that the world's financial and banking services have gone through a paradigm shift, thanks to Machine Learning (ML) and Artificial Intelligence (A.I.). Notably, fintech organizations' growth plays a leading role in the transformation we see unfolding before our own eyes. For instance, a recent Q2 report of India's fintech industry revealed a massive investment in the sector with 32 deals sealed in the same period, which clearly shows the financial services system's growth. While traditional banking institutions are quickly catching up with the computational intelligence technologies with products like Chatbot, fintech companies, which seem to have embrace A.I. a long time ago, plays a critical role through its innovation and contribute substantially to financial intelligence (Das et al., 2015).

First of all, we need to understand what A.I. and ML are. Well, John McCarthy, the father of Artificial Intelligence (A.I.), puts it aptly as, "The science and engineering of making intelligent machines, especially intelligent computer programs" (Kumar \& Chandrakala, 2016). Broadly speaking, A.I. is all about making a computer or turning a computer into a robot, or a set of programming codes designed to make computers think and behave intelligently like humans. A.I. is the process of developing intelligent computer software and systems to mimic humans by studying how humans think, how they learn, and their mental ability in solving a problem. In other words, Artificial Intelligence is creating Intelligent Quotient (I.Q.) and Emotional Quotient (E.Q.) in computers. Though A.I. and ML are sometimes used interchangeably, they mean two different things.

Many people believe that machine learning was founded on the premise that machines can somehow learn. And according to history, the central tenets of machine learning, and by extension, Artificial Intelligence shows that the two have been around for more than half a century now. Arthur Samuel, an IBM scientist, first applied Machine Learning in 1959, when he published a solution to checkers' game (Arthur Samuel, 1959). In his explanation, for the first time in history, a computer could play checkers with humans and actually win. Over the years, programmers have built more sophisticated systems enabling machines to do what humans can. Another notable example is a board game 'Go', which has been around for more than 2500 years, and for some reason, it was believed to be more complicated and strategic than chess; hence no computer could defeat a human in the game of "Go". Well, that belief was shattered four years ago, when AlphaGo, a computer program, brought down an 18-time world champion in an emphatic defeat of 4 to 1 (Taher-Uz-Zaman et al., 2014).

Machine learning in the banking sector has accelerated changes in how business is done. Machine learning in this field analyzes historical data and behaviors to predict patterns and aid in the decision-making process (SEC Speech, 2016).

\section{Role of ARtificial INTELLIgence AND MACHINe LeARNing IN BANKING}

As the financial institutions continue to embrace A.I. and ML, we see the application spectrum of these two technologies rising each day. However, the potential risks posed by these two are also increasing. Computational intelligence technology is not only taking over the banking industry but also other sectors such as insurance companies and capital markets. A.I. and ML are majorly used in the banking industry for automation, analysis, and decision-making, thereby creating new business models. A study done by Purdy \& 
Daugherty (2016) revealed that A.I. and ML applications would dictate how banks will interact with their customers in the future. Another research by BCG consulting group shows that China is way ahead of other countries in the application of A.I. and ML in their financial sector, especially fintech. The research shows that by $202723 \%$ of their job market in finance will have changed, with A.I. and ML playing a pivotal role in enhancing efficacy and automation process. Here are some applications of Artificial Intelligence (A.I.) and Machine Learning (ML) in Banking (Yu et al., 2016).

\section{AML and Fraud Pattern Detection}

Anti-Money Laundering (AML) refers to a set of procedures, laws, or regulations designed to stop the practice of generating income through illegal means. Most banks use A.I. based systems, which are more robust and intelligent to the AML patterns. With continuous innovations and improvements in the field of A.I., these systems are set to become more accurate and faster. Actually, many countries are now embracing the power of A.I. and ML in fraud detection. A notable example is the National Stock Exchange of India, which recently announced that they are putting in place policies to pave the way for utilizing machine learning to identify market patterns, monitoring on the exchange to prevent manipulation of its Frequency Trading (HFT) markets. They are working on upgrading their surveillance system with A.I. and ML to strengthen their security.

\section{Personalized Banking and Automation}

Perhaps this is an area where A.I. has really shine with its innovations and ways to offer easier access and comfort to banking users. Notably, A.I. is taking the banking industry by storm through personalized services to clients such as chatbots, which provide self-help solutions, thus reducing workload to the call-centers. Today, voice-controlled virtual assistants are providing smarter services to clients in whatever transactions they are doing. Be it checking balances, schedule payments, looking up account activity, and so on. Besides, there are plenty of apps in the market nowadays offering personalized financial advice. We now have an A.I. application system that tracks personal income, monthly expenses, your spending habits, and offers suggestions with an optimized plan and financial tips. No wonder industry leaders are now putting forth robotic process automation as a part of their future plans to reduce operational cost and boost productivity with intelligent character recognition. A.I. and ML adoption in the banking sector eliminates human error in high-frequency repetitive tasks.

\section{Customer recommendations}

Computational intelligence has also rendered an essential contribution to recommendation engines in the banking sector. It is based on using data from the past about users to make the most appropriate user recommendation based on their preferences and the user's history. Since time immemorial, recommendation engines have played a major role in revenue growth enjoyed by many banks.

\section{Risk Management}

The building tenets of A.I. and ML are learning from past data. Therefore, it is natural that ML and A.I. are sweeping over the banking sector, where bookkeeping and records are their second name. For instance, how credit cards work. For far too long, we've used credit score as a means of deciding who qualifies for a credit card and who does not. However, this technique classifies people into 'haves' and 'have nots', which is not good for business. Instead, what the banking sector can do is collect data about each individual's loan repayment habits, the number of loans he/she is currently servicing, how many credit cards he/she has, and so on. 
This data could be used to customize the interest rate on a card, making more sense to the institution offering it. This is where A.I. and ML come in; think about a system in the world that can go through thousands of personal financial records to come up with a solution. It is a learned machine. A.I. is a data-driven and data-dependent giant, and therefore, it can analyse thousands of records and recommend loan credit offerings (Bauguess et al., 2017).

\section{CONCLUSION}

In conclusion, we can aptly say that Machine Learning and Artificial Intelligence technologies are taking over the banking sector, and it seems like there's nothing we can do about it. The two computational intelligence are aiding in rewriting how we interact with our money. A.I. and ML have given the banking sector a new way of meeting their customers' demands, who are looking for smarter, convenient, and safer ways to access, save, spend, and invest their money. It is, therefore, up to the financial institutions to heed the call of the new era. Customers are a smart lot nowadays. They have realized that technology is not expensive or complicated to learn; everything is bundled together in a smartphone that an ordinary man can easily operate (Donepudi, 2017).

\section{REFERENCES}

Arthur Samuel (1959). Some Studies in Machine Learning Using the Game of Checkers. IBM Journal 3, (3): 210-229. https://ssrn.com/abstract=3226514

Bauguess, Scott W., The Role of Big Data, Machine Learning, and A.I. in Assessing Risks: A Regulatory Perspective (June 21, 2017). SEC Keynote Address: OpRisk North America 2017. http://dx.doi.org/10.2139/ssrn.3226514

Castelli, M., Manzoni, L., \& Popovic, A. (2016). An artificial intelligence system to predict quality of service in banking organizations. Computational Intelligence and Neuroscience: CIN, 2016. http://dx.doi.org/10.1155/2016/9139380

Das, S., Dey, A., Pal, A., \& Roy, N. (2015). Applications of artificial intelligence in machine learning: Review and prospect. International Journal of Computer Applications, 115(9) http://dx.doi.org/10.5120/20182-2402

Donepudi, P. (2016). Influence of Cloud Computing in Business: Are They Robust? Asian Journal of Applied Science and Engineering, 5(3), 193-196. https://doi.org/10.5281/zenodo.4110309

Donepudi, P. (2017). AI and Machine Learning in Banking: A Systematic Literature Review. Asian Journal of Applied Science and Engineering, 6(3), 157-162. https://doi.org/10.5281/zenodo.4109672

Kumar, A. S. \& Chandrakala, D. (2016). A survey on customer churn prediction using machine learning techniques. International Journal of Computer Applications, 154(10) http://dx.doi.org/10.5120/ijca2016912237

Purdy M. \& Daugherty, P. (2016). Why artificial intelligence is the Future of Growth. Accenture, Available online at https://www.accenture.com/t20170524t055435 w /ca-en/ acnmedia/pdf52/accenture-why-ai-is-the-future-of-growth.pdf

SEC Speech, Has Big Data Made Us Lazy?, Midwest Region Meeting of the American Accounting Association, October 2016. https://www.sec.gov/news/speech/bauguess-americanaccounting-association-102116.html

Taher-Uz-Zaman, M., Ahmed, M. S., Hossain, S., Hossain, S., \& Jamal, G. R. A. (2014). Multipurpose Tactical Robot. Engineering International, 2(1), 21-27. https://doi.org/10.18034/ei.v2i1.204

Yu, L., Yang, Z., \& Tang, L. (2016). A novel multistage deep belief network based extreme learning machine ensemble learning paradigm for credit risk assessment. Flexible Services and Manufacturing Journal, 28(4), 576-592. http://dx.doi.org/10.1007/s10696-015-9226-2

$--0--$ 